\title{
Cirurgia da catarata infantil unilateral
}

\author{
Unilateral pediatric cataract surgery
}

\author{
Adriana Maria Drummond Brandão ${ }^{1}$ \\ Márcia Beatriz Tartarella ${ }^{2}$
}

Trabalho realizado no ambulatório de Catarata Congênita do Departamento de Oftalmologia da Universidade Federal de São Paulo - UNIFESP.

${ }^{1}$ Fellow do Serviço de Catarata Congênita e Mestre em Administração da Prática Oftalmológica pelo Departamento de Oftalmologia da Universidade Federal de São Paulo - UNIFESP - São Paulo (SP) - Brasil.

2 Chefe do Serviço de Catarata Congênita e Doutor pelo Departamento de Oftalmologia da UNIFESP - São Paulo (SP) - Brasil.

Endereço para correspondência: Adriana M. D. Brandão. Rua Diógenes Malacarne, 150/304 - Vila Velha (ES) CEP 29101-210

E-mail: amdbrandao@terra.com.br

Recebido para publicação em 23.06.2006

Última versão recebida em 01.10 .2007

Aprovação em 22.11.2007

Nota Editorial: Depois de concluída a análise do artigo sob sigilo editorial e com a anuência do Dr. Mauro Waiswol sobre a divulgação de seu nome como revisor, agradecemos sua participação neste processo.

\section{RESUMO}

Objetivo: Analisar os resultados visuais de uma série de crianças operadas de catarata unilateral. Métodos: Um estudo retrospectivo foi realizado através da análise de 35 prontuários médicos do Serviço de Catarata Congênita da UNIFESP/EPM. Resultados: Quanto à etiologia, a primeira causa de catarata foi idiopática, a segunda causa foi o trauma e a terceira foi a rubéola congênita. Em 51,4\% dos olhos tinham acuidade visual pré-operatória de ausência de fixação. E em 42,8\% dos casos operados a acuidade visual final foi igual ou melhor que 20/200. Discussão: Embora a cirurgia em catarata unilateral seja motivo de controvérsias entre os oftalmologistas, obteve-se melhora de acuidade visual em número significativo de casos.

Descritores: Catarata/congênita; Extração de catarata/métodos; Acuidade visual; Testes visuais; Prognóstico; Resultado de tratamento; Criança; Pré-escolar

\section{INTRODUÇÃO}

A cegueira causada por catarata congênita e infantil apresenta-se como um enorme problema em países em desenvolvimento ${ }^{(1)}$. A catarata congênita é uma das causas mais comuns de cegueira evitável na infância ${ }^{(2)}$.

Programas de vacinação contra a rubéola e o diagnóstico e tratamento precoce podem diminuir a incidência de cegueira por catarata na infância ${ }^{(3)}$.

O tratamento da catarata na infância representa um desafio para os oftalmologistas, porque as dificuldades na cirurgia e a propensão de desenvolver inflamação no período pós-operatório, aumentam em olhos de crianças. Estas dificuldades somam-se com a instalação da ambliopia e contribuem para dificultar a obtenção de um bom resultado visual ${ }^{(1)}$.

Em 1963, após alguns estudos ${ }^{(4)}$ ficou determinado que existe um período desde o nascimento, para o desenvolvimento do reflexo de fixação que termina entre o $2^{\circ}$ e o $4^{\circ}$ mês de vida e que a privação visual neste intervalo, leva à atrofia do corpo geniculado lateral e conseqüentemente à ambliopia irreversível $^{(5)}$.

O mecanismo da instalação da ambliopia na catarata unilateral é múltiplo, pois pode associar à privação visual pela catarata, à anisometropia e ao estrabismo. Estes três fatores indutores de ambliopia quando associados, acarretam uma perda visual mais grave, que exige tratamento e reabilitação precoce.

O nistagmo ou a perda do reflexo de fixação que se desenvolve como resultado da catarata congênita, pode diminuir após a remoção cirúrgica da catarata e do tratamento pós-operatório da ambliopia ${ }^{(2)}$.

Os resultados visuais do tratamento da catarata congênita bilateral apresentam um prognóstico melhor em relação à catarata unilateral: em uma série de 17 crianças operadas de catarata congênita unilateral, a melhor acuidade 
obtida foi 20/400, mesmo nos casos em que a cirurgia de catarata congênita unilateral foi realizada precocemente, antes dos três meses de idade ${ }^{()}$.

O objetivo deste trabalho, foi avaliar os resultados visuais do tratamento da catarata infantil unilateral.

\section{MÉTODOS}

Foram analisados os prontuários das crianças atendidas no Serviço de Catarata Congênita da UNIFESP/EPM, no período de fevereiro de 1990 a junho de 2002.

Foram incluídas neste estudo 35 crianças operadas de catarata unilateral, no Hospital São Paulo com as seguintes técnicas cirúrgicas: lensectomia, facectomia (FEC), facectomia com implante de LIO (FEC + LIO) e facoemulsificação com implante de LIO (FACO + LIO).

Excluíram-se crianças que não tiveram acompanhamento pós-operatório de no mínimo 1 mês.

A acuidade visual estabelecida como pré-operatória foi aquela obtida na primeira consulta e como acuidade final, a acuidade visual obtida na última consulta, com a melhor correção óptica de cada paciente.

A acuidade visual foi avaliada em crianças pré-verbais, pelos seguintes métodos: fixação e seguimento de foco luminoso e objetos, teste de acuidade de resolução de grades com cartões de Teller e potencial visual evocado de varredura. Estes últimos tiveram seus níveis de acuidade transformados para a medida fracionada (exemplo: 20/200). Nas crianças verbais foram realizados testes de reconhecimento com figuras e a tabela E de Snellen ou com letras.

Em todos os casos a correção óptica da afacia foi realizada por meio da prescrição de óculos, lente de contato ou lente intra-ocular; ou a combinação dos mesmos.

Foi prescrito tratamento oclusivo do olho contralateral para todos pacientes, com duração de metade do seu dia ativo (meio período).

Considerou-se catarata congênita, os casos examinados no ambulatório em crianças menores de 3 meses, e os casos em que a história relatava sinais como leucocoria, estrabismo ou nistagmo presentes antes dos 6 meses de idade. As cataratas adquiridas foram consideradas como o grupo de crianças que apresentavam catarata secundária ao trauma ou outras afecções oculares.

\section{RESULTADOS}

Trinta e cinco crianças foram operadas de catarata unilateral, sendo 24 cataratas congênitas (68,6\%), e 11 adquiridas $(31,4 \%)$.

A idade na cirurgia variou de 3 meses até 13 anos, média: 6 anos e 6 meses.

O intervalo de seguimento entre a cirurgia e a última acuidade visual obtida no prontuário, variou de no mínimo 1 mês até 6 anos (média $=36$ meses).
Em relação ao sexo: 19 crianças eram do sexo feminino $(54,3 \%)$ e 16 eram do masculino $(45,7 \%)$, sem diferença estatística significante.

Em relação ao olho operado: 21 , olho direito $(60 \%)$ e 14 , olho esquerdo (40\%).

Trinta crianças apresentavam alteração da motilidade ocu$\operatorname{lar}(85,7 \%)$ e 5 apresentavam motilidade ocular normal $(14,3 \%)$. Exotropia em 17 crianças e endotropia em 13 crianças. Nistagmo estava presente em 3 crianças.

Pela história clínica, a idade de aparecimento da catarata variou de 1 semana de vida até 9 anos de idade.

O intervalo entre a idade de aparecimento da catarata e a primeira consulta no ambulatório especializado variou de 1 mês até 12 anos.

As causas de catarata congênita foram: idiopáticas, 15 (62,5\%); rubéola, 3 (12,5\%); uso de medicamentos na gestação, 2 (8,3\%); familiar, 2 (8,3\%); vítreo primário persistente hiperplásico, 1 (4,2\%); síndrome genética, 1 (4,2\%).

As causas de catarata adquirida foram: trauma, $7(63,6 \%)$; pós-tratamento para retinoblastoma, $2(18,2 \%)$; pós-cirurgia antiglaucomatosa, $1(9,1 \%)$ e pós-uveíte, $1(9,1 \%)$.

Quanto à morfologia, em 20 casos $(57,2 \%)$ a catarata era total, em $6(17,1 \%)$ lamelar, em $3(8,6 \%)$ polar posterior, em $2(5,7 \%)$ nuclear, em $1(2,85 \%)$ polar anterior, em $1(2,85 \%)$ piramidal, em $1(2,85 \%)$ zonular e em $1(2,85 \%)$ capsular posterior .

As técnicas das cirurgias realizadas foram: facoemulsificação com implante de LIO em 15 casos (42,9\%), facectomia com implante de LIO em 11 casos $(31,4 \%)$, lensectomia em $6(17,1 \%)$ e facectomia em $3(8,6 \%)$.

$\mathrm{Na}$ tabela 1 está apresentada a acuidade visual pré-operatória e a acuidade visual final, com a melhor correção óptica.

Para melhor análise, os resultados da acuidade visual foram divididos em grupos. A tabela 2 mostra os resultados visuais finais, nas cataratas congênitas e a tabela 3, nas cataratas adquiridas. Na tabela 4 estão apresentados os resultados das acuidades visuais, do grupo de crianças com catarata congênita divididos conforme a faixa etária na ocasião da cirurgia, crianças operadas até 1 ano de idade e crianças maiores de 1 ano.

\section{DISCUSSÃO}

Alguns autores observaram um grande número de casos de catarata infantil por doenças infecciosas na gestação, destacando a rubéola com o maior número de casos. Neste estudo é a terceira maior causa de catarata unilateral $(8,6 \%)$ e a segunda causa entre as cataratas congênitas ${ }^{(6)}$.

Em relação ao tipo da catarata, a catarata lamelar é o tipo mais comum de opacidade congênita do cristalino $^{(7)}$ e neste estudo aparece em $17,1 \%$ do total das cataratas unilaterais.

Outros autores relataram que o trauma ocular é uma importante causa na infância de catarata unilateral nos países em desenvolvimento, coincidindo com este estudo, onde encontra- 


\begin{tabular}{|c|c|c|c|c|}
\hline Acuidade visual & Pré-operatória & $\%$ & Final & $\%$ \\
\hline Ausência de fixação & 18 & $51,4 \%$ & 1 & $2,90 \%$ \\
\hline Percepção de luz & 4 & $11,4 \%$ & 2 & $5,70 \%$ \\
\hline $\begin{array}{l}\text { Movimento de } \\
\text { mãos e/ou vultos }\end{array}$ & 4 & $11,4 \%$ & 4 & $11,42 \%$ \\
\hline Conta-dedos & 6 & $17,2 \%$ & 6 & $17,10 \%$ \\
\hline $20 / 600$ a $20 / 250$ & 1 & $2,9 \%$ & 7 & $20,00 \%$ \\
\hline $20 / 200$ a 20/150 & 2 & $5,7 \%$ & 4 & $11,42 \%$ \\
\hline $20 / 100$ a $20 / 60$ & 0 & 0 & 8 & $22,86 \%$ \\
\hline $20 / 50$ a $20 / 20$ & 0 & 0 & 3 & $8,60 \%$ \\
\hline Total & 35 & $100,0 \%$ & 35 & $100,0 \%$ \\
\hline
\end{tabular}

\begin{tabular}{|lcrrr|}
\hline \multicolumn{5}{|c}{ Tabela 2. Acuidade visual pré e pós-operatória na catarata congênita } \\
\hline $\begin{array}{l}\text { Acuidade visual } \\
\text { Ausência de fixação }\end{array}$ & Pré-operatória & $\%$ & Final & $\%$ \\
\hline $\begin{array}{l}\text { Percepção de luz } \\
\text { Movimento de }\end{array}$ & 16 & $66,6 \%$ & 0 & 0 \\
mãos e/ou vultos & 1 & $8,3 \%$ & 3 & $12,0 \%$ \\
Conta-dedos & & $4,2 \%$ & 1 & $4,0 \%$ \\
$20 / 600$ a 20/250 & 3 & $12,5 \%$ & 5 & $21,0 \%$ \\
$20 / 200$ a 20/150 & 0 & 0 & 6 & $25,0 \%$ \\
$20 / 100$ a 20/60 & 1 & $4,2 \%$ & 3 & $12,5 \%$ \\
$20 / 50$ a 20/20 & 1 & $4,2 \%$ & 5 & $21,0 \%$ \\
Total & 0 & 0 & 1 & $4,0 \%$ \\
& 24 & $100,0 \%$ & 24 & $100,0 \%$ \\
\hline
\end{tabular}

\begin{tabular}{|c|c|c|c|c|}
\hline $\begin{array}{l}\text { Acuidade } \\
\text { visual }\end{array}$ & $\begin{array}{l}\text { Pré- } \\
\text { operatória }\end{array}$ & $\%$ & $\begin{array}{l}\text { Pós- } \\
\text { operatória }\end{array}$ & $\%$ \\
\hline Ausência de fixação & 2 & $18,2 \%$ & 0 & 0 \\
\hline Percepção de luz & 2 & $18,2 \%$ & 0 & 0 \\
\hline $\begin{array}{l}\text { Movimento de } \\
\text { mãos e/ou vultos }\end{array}$ & 3 & $27,3 \%$ & 3 & $27,3 \%$ \\
\hline Conta-dedos & 3 & $27,3 \%$ & 1 & $9,0 \%$ \\
\hline $20 / 600$ a $20 / 250$ & 1 & $9,0 \%$ & 2 & $18,2 \%$ \\
\hline $20 / 200$ a $20 / 150$ & 0 & 0 & 1 & $9,0 \%$ \\
\hline $20 / 100$ a $20 / 60$ & 0 & 0 & 2 & $18,2 \%$ \\
\hline $20 / 50$ a $20 / 20$ & 0 & 0 & 2 & $18,2 \%$ \\
\hline Total & 11 & $100,0 \%$ & 11 & \\
\hline
\end{tabular}

\begin{tabular}{|c|c|c|c|c|}
\hline $\begin{array}{l}\text { Acuidade } \\
\text { visual }\end{array}$ & $\begin{array}{c}\text { Antes de } 1 \\
\text { ano de idade }\end{array}$ & $\%$ & $\begin{array}{l}\text { Depois } \\
\text { ano de ic }\end{array}$ & $1 \%$ \\
\hline Ausência de fixação & 0 & 0 & 0 & 0 \\
\hline Percepção de luz & 2 & $22,2 \%$ & 1 & $7 \%$ \\
\hline $\begin{array}{l}\text { Movimento de } \\
\text { mãos e/ou vultos }\end{array}$ & 0 & 0 & 1 & $7 \%$ \\
\hline Conta-dedos & 3 & $33,3 \%$ & 2 & $13 \%$ \\
\hline $20 / 600$ a $20 / 250$ & 3 & $33,3 \%$ & 3 & $20 \%$ \\
\hline $20 / 200$ a $20 / 150$ & 0 & 0 & 4 & $26 \%$ \\
\hline $20 / 100$ a $20 / 60$ & 1 & $11,2 \%$ & 3 & $20 \%$ \\
\hline $20 / 20$ a $20 / 20$ & 0 & 0 & 1 & $7 \%$ \\
\hline Total & 9 & $100,0 \%$ & 15 & $100 \%$ \\
\hline
\end{tabular}

mos a etiologia traumática em $20 \%$ do total de casos e em $63,6 \%$ entre as cataratas adquiridas ${ }^{(3)}$.

Quando há trauma ocular com ruptura da cápsula do cristalino, este torna-se hidratado e cataratoso dentro de horas ${ }^{(7)}$.

$\mathrm{Na}$ afacia de origem traumática, o prognóstico visual é melhor, pois já houve o desenvolvimento das estruturas nervosas da retina e vias ópticas ${ }^{(8)}$.

Para a correção da afacia, os óculos não são a solução ideal porque resulta em alterações na perifeira do campo visual e aumento da imagem em relação ao olho normal ${ }^{(7)}$.

Para as crianças do ambulatório da UNIFESP/EPM, o uso de lentes de contato para correção da afacia constitui-se em tratamento inviável e oneroso, mas foi possível prescrever óculos e tratamento oclusivo ${ }^{(9)}$.

Alguns autores advogam cirurgia para os casos unilaterais somente até os 2 meses de vida e outros indicam a cirurgia na presença de olhos alinhados independentemente da idade.

Alguns estudiosos ${ }^{(10)}$ optaram por contra-indicar a cirurgia nos casos de catarata unilateral mas outros ${ }^{(11)}$ ressaltaram que a cooperação visual binocular pode ser obtida em crianças com afacia unilateral quando operadas precocemente.

Há cirurgiões que contra-indicam a cirurgia em qualquer catarata congênita unilateral ${ }^{(12)}$. Há outros que indicam a cirurgia em qualquer catarata congênita unilateral, mesmo incipiente ${ }^{(13)}$

Segundo alguns pesquisadores aproximadamente $50 \%$ dos pacientes com catarata congênita unilateral que tinham olhos alinhados e nenhum estrabismo, obtiveram visão final de $20 / 40$ ou melhor ${ }^{(9)}$.

O estrabismo pode aparecer em $40 \%$ das cataratas infantis bilaterais e em $90 \%$ das cataratas unilaterais ${ }^{(14)}$.

Em relação à motilidade ocular, 30 crianças $(85,7 \%)$ do total de 35 estudadas neste trabalho, apresentavam estrabismo e/ou nistagmo que são sinais indicativos de baixa visão e pior prognóstico visual pós-operatório.

Neste estudo, entre as crianças com catarata congênita unilateral operadas antes de 1 ano de idade, apenas 11,1\% apresentaram acuidade visual igual ou melhor que 20/100. As crianças operadas após 1 ano de idade apresentaram 53,3\% de visão melhor ou igual a 20/200.

Nos casos de catarata unilateral adquirida, a acuidade visual pós-operatória, melhor que 20/200, foi obtida em 45,5\% dos casos. As crianças portadoras de retinoblastoma apresentavam baixa acuidade visual devido às lesões tumorais e à retinopatia por irradiação. A criança com glaucoma e a com uveíte, anteriores à cirurgia de catarata, também apresentavam alterações oculares decorrentes da patologia prévia que diminuíram a taxa de sucesso visual pós-operatório.

As cataratas unilaterais do tipo lamelar, lenticone posterior e vítreo primário persistente hiperplásico, que são freqüentemente parciais ao nascimento, podem progredir com o tempo. E podem permitir o desenvolvimento visual preco$\mathrm{ce}^{(9)} \mathrm{e}$ apresentar resultados visuais satisfatórios mesmo sendo operadas após o período crítico de desenvolvimento visual. 
Os resultados visuais pós-operatórios esperados não são satisfatórios se não houver adequado diagnóstico e tratamento da ambliopia. A terapia oclusiva requer correção visual com óculos ou lentes de contato e oclusão parcial do olho com melhor acuidade visual.

Alguns autores reconhecem a terapia com oclusão do olho com melhor visão como eficiente na melhora do desenvolvimento visual de olhos submetidos à cirurgia de catarata unilateral, mas que haveria a possibilidade de ocasionar iatrogenia na acuidade visual do olho ocluído sem o devido acompanhamento $^{(15)}$

Outros autores recomendam um esquema de oclusão menos intenso para favorecer a interação binocular ${ }^{(11)}$.

Observamos neste estudo que algumas crianças não continuaram o seguimento no ambulatório após a cirurgia e podemos supor que não continuaram suas terapias antiambliopia, diminuindo as chances de recuperação visual. Sugerimos que os familiares sejam informados e orientados antes da indicação da cirurgia, para que ocorra uma decisão em conjunto e uma melhor colaboração no pós-operatório.

Nesta série, em $42,9 \%$ do total de olhos, a visão obtida foi igual ou melhor que 20/200. Os resultados visuais dependem de muitas variáveis clínicas, incluindo faixa etária, etiologia, padrão morfológico da catarata, técnica cirúrgica e adesão ao tratamento oclusivo. Cada caso de catarata unilateral em crianças deve ser avaliado individualmente para a decisão da conduta a ser tomada buscando o benefício da criança e ponderando os riscos oculares e sistêmicos.

Os familiares e os profissionais de saúde e reabilitação visual ligados às crianças com catarata unilateral devem estar cientes das dificuldades do tratamento e da possibilidade de baixa visual no pós-operatório e concordarem com a conduta proposta.

\section{CONCLUSÕES}

Neste estudo em 35 crianças operadas de catarata unilateral, 11 crianças $(31,4 \%)$ tinham catarata adquirida e $24(68,6 \%)$ catarata congênita.

$\mathrm{Na}$ catarata congênita, $37,5 \%$ das crianças obtiveram acuidade visual igual ou melhor que 20/200.

No total dos olhos com catarata unilateral operados, em $42,8 \%$ dos casos o resultado da acuidade visual foi igual ou melhor que 20/200.

\section{ABSTRACT}

Purpose: To analyze the results in a series of children submitted to unilateral cataract surgery. Methods: A retrospective study was conducted through the analysis of 35 patient files from the Congenital Cataract Service of UNIFESP/EPM. Results: The main cause of unilateral cataract was idiopathic, the second cause was ocular trauma and the third cause was congenital rubella. Initial visual acuity was very poor in $51.4 \%$ of the cases (did not fix or follow), and the best corrected final visual acuity was better than 20/200 in 42.8\% of the eyes. Discussion: Although controversial, the surgical treatment of unilateral cataract, in this study, showed improvement in many cases.

Keywords: Cataract/congenital; Cataract extraction/methods; Visual acuity; Vision tests; Prognosis; Treatment outcome; Child; Child, preschool

\section{REFERÊNCIAS}

1. Wilson ME, Pandey SK, Thakur J. Paediatric cataract blindness in the developing world: surgical techniques and intraocular lense in the new millennium. Br J Ophthalmol. 2003;87(1):14-9.

2. Good WV. Cataract surgery in young children. Br J Ophthalmol. 2001; 85(3):254. Comment on: Br J Opthalmol. 2001;85(3):267-71.

3. Apple DJ, Ram J, Foster A, Peng Q. Elimination of cataract blindness: a global perspective entering the new millennium. Surv Ophthalmol. 2000; 45(Suppl 1): S1-196.

4. Wiesel TN, Hubel DH. Effects of visual deprivation on morphology and physiology of cells in the cat's lateral geniculate body. J Neurophysiol. 1963;26:978-93.

5. Kitadai SP, Bonomo PP. Catarata congênita: frequiência etiológica. Arq Bras Oftalmol. 1994:57(6):404-6.

6. Tartarella MB, Kawakami LT, Scarpi MJ, Hayashi S. Aspectos cirúrgicos em catarata congênita. Arq Bras Oftalmol. 1995;58(1):24-8.

7. Catalano RA, Nelson LB. Pediatric Ophthalmology: a text atlas. New York: Applenton \& Lange; 1994.

8. Moreira CA, Moreira SM, Moreira Junior CA. Correção óptica da afacia na infância. Arq Bras Oftalmol. 1986;49(6):188-90.

9. Taylor D, Wrigt KW, Amaya L, Cassidy L, Nischal K, Russell-Eggitt I, et al. Should we aggressively treat unilateral congenital cataracts? $\mathrm{Br} \mathrm{J}$ Ophthalmol. 2001;85(9):1120-6. Review.

10. Maia NC, Baikoff G. Catarata congênita: técnicas e indicações cirúrgicas. Rev Bras Oftalmol. 1998;57(7):565-71.

11. Brown SM, Archer S, Del Monte MA. Stereopsis and binocular vision after surgery for unilateral infantile cataract. J AAPOS. 1991;(2):109-13.

12. Arias-Puente A. Catarata congênita [resumo]. In: $8^{\circ}$ Congresso Internacional de Catarata e Cirurgia Refrativa; 2004 abril 21-24; Recife.

13. Kuri JV. Novos critérios no manejo cirúrgico da catarata congênita [resumo]. In: $8^{\circ}$ Congresso Internacional de Catarata e Cirurgia Refrativa; 2004 abril 21-24; Recife.

14. Tartarella, MB. Tratamento clínico e cirúrgico: experiência na Escola Paulista de Medicina [resumo] In: $8^{\circ}$ Congresso Internacional de Catarata e Cirurgia Refrativa; 2004; abril 21-24; Recife.

15. Thompson DA, Moller H, Russel-Eggitt I, Kriss A. Visual acuity in unilateral cataract. Br J Ophthalmol. 1996:80(9):794-8. 